\section{Case Reports in Neurology}

Case Rep Neurol 2020;12:428-432

DOI: $10.1159 / 000510633$

Published online: November 12, 2020 (c) 2020 The Author(s)

Published by S. Karger AG, Basel www.karger.com/crn

This article is licensed under the Creative Commons Attribution-NonCommercial 4.0 International License (CC BY-NC) (http://www.karger.com/Services/OpenAccessLicense). Usage and distribution for commercial purposes requires written permission.

\title{
Rare Case of Late-Onset Narcolepsy Type 1
}

\author{
Petra Kovalskáa Simona Dostálováa Hana Machováb Petra Nytrováa \\ Eszter Maurovich Horvat ${ }^{a}$ Karel Šonka ${ }^{a}$ \\ aDepartment of Neurology and Centre of Clinical Neuroscience, First Faculty of Medicine, \\ Charles University and General University Hospital in Prague, Prague, Czech Republic; \\ bInspamed, Ltd., Institute of Sleep Medicine, Prague, Czech Republic
}

\section{Keywords}

Narcolepsy with cataplexy · Elderly · Rare case

\begin{abstract}
A 69-year-old male developed symptoms typical of the diagnosis of narcolepsy type 1 without any previous triggering events. First, daytime sleepiness occurred, soon followed by cataplexy. Nocturnal polysomnography revealed rapid eye movement (REM) sleep behavior disorder, a apnea-hypopnea index of 25.8 events/h, and no sleep-onset REM. Multiple Sleep Latency Test showed a mean sleep latency of $2.1 \mathrm{~min}$ and REM sleep in 3 tests. HLA DQB1*06:02 was positive and hypocretin-1 in cerebrospinal fluid unmeasurable. A treatment with $50 \mathrm{mg}$ clomipramine controlled the cataplexy; excessive daytime sleepiness was sufficiently managed by repeated naps. The administration of $0.25 \mathrm{mg}$ of clonazepam subjectively improved REM sleep behavior disorder. Bilevel Positive Airway Pressure improved the apnea-hypopnea index without important influence on sleepiness. Our unique case demonstrates that even elderly subjects can develop narcolepsy type 1 .

(c) 2020 The Author(s) Published by S. Karger AG, Basel
\end{abstract}

\section{Introduction}

Narcolepsy type 1 (NT1; older name: narcolepsy with cataplexy [NC]) is a life-long neurological disease characterized by excessive daytime sleepiness (EDS), disrupted nocturnal 


\section{Case Reports in Neurology}

Case Rep Neurol 2020;12:428-432

DOI: $10.1159 / 000510633$

(c) 2020 The Author(s). Published by S. Karger AG, Basel www.karger.com/crn

Kovalská et al.: Rare Case of Late-Onset Narcolepsy Type 1

sleep, and cataplexy. It is often accompanied by hypnagogic hallucinations and sleep paralysis. The disease is caused by the loss of hypocretin neurons in the lateral hypothalamus. The disappearance of hypocretin neurons is suggested to have an autoimmune etiology [1]. The typical age at onset is in the second decade and another smaller peak in the fourth decade [2]. Possible later onset is indicated as rare throughout studies; in Roth [3], only 4 out of 288 cases had onset after 50 years. To our knowledge, only 3 cases of NC onset at around age 70 years have been described: all of them are not clinically clear [4,5]. We would like to present an undoubtedly diagnosed late-onset NT1 in a 69-year-old male subject.

\section{Case Report}

Our patient was previously treated for chronic obstructive pulmonary disease, arterial hypertension, and dyslipidemia, with a history of deep vein thrombosis. He smokes about 20 cigarettes a day and occasionally likes to drink a couple of beers. Our patient has already been retired for several years from his previous occupation as a tiler. He lives with his wife and likes fishing. The patient started to suffer from EDS at the age of 69 years. No possible trigger, such as trauma, infectious disease, vaccination, or other serious health or social event, preceded the manifestation of his symptoms. Within 2 or 3 months, his symptoms got more severe so that he contacted a sleep disorder center and was sent to our clinic, where he was completely examined and diagnosed (just after his 70th anniversary).

The patient described a sudden onset of disturbing daytime sleepiness and required several 5- to 10-min naps throughout the day. He fell asleep while engaged in monotonous activities, such as TV watching, reading, or using an iPad. However, sleep attacks while he was physically active did not occur. He tried to avoid falling asleep unexpectedly by taking a short nap in advance. Being already retired, the sleepiness did not present important difficulties in his life. He made a few complaints about disturbed nocturnal sleep, especially frequent vivid dreams and dream enactment behavior. For example, he reported waking up and petting an imaginary dog that he had been dreaming of.

Approximately 2 months after EDS onset, the patient started experiencing symmetrical muscle tone weakness triggered by emotion. For example, he described short episodes of weakness in his upper and lower extremities when catching a fish. In another example, he claimed while telling a joke, that he sometimes lost the ability to speak before finishing the punchline. These episodes of cataplexy occurred several times a day. In a few cases, he was even injured due to falls. The cataplexy episodes usually lasted from a few seconds to up to 4 min. Four mild cataplectic episodes were observed by a physician during his first consultation. The patient did not experience hypnagogic hallucinations or sleep paralysis. The patient gained $10 \mathrm{~kg}$ within a year without changing his diet and his body mass index reached 35.2.

Objective neurological examination did not reveal any important neurological, physical, nor cognitive findings. The nocturnal polysomnography showed sleep fragmentation (a sleep effectivity of 73\%) and rapid eye movement (REM) sleep without atonia with behavioral manifestations (somniloquy, gesticulations, upper limb complex movements) corresponding to REM sleep behavior disorder (RBD). No sleep-onset REM (SOREM) during the night was seen (REM sleep latency was $117 \mathrm{~min}$ ). Obstructive apneas were found with an apnea-hypopnea index of 25.8 events/h with low saturation (basal saturation $92 \%, 62 \%$ of time below $90 \%$ saturation [T90]). On the following day, Multiple Sleep Latency Test (MSLT) confirmed EDS. The patient fell asleep in all 5 tests with a mean sleep latency of $2.1 \mathrm{~min}$. Three tests showed SOREM. Surprisingly, he scored 7 points on the Epworth Sleepiness Scale (ESS). HLA 


\section{Case Reports in Neurology}

Case Rep Neurol 2020;12:428-432

DOI: $10.1159 / 000510633$

(c) 2020 The Author(s). Published by S. Karger AG, Basel www.karger.com/crn

Kovalská et al.: Rare Case of Late-Onset Narcolepsy Type 1

DQB1*06:02 was positive. The level of hypocretin in cerebrospinal fluid (CSF) was immeasurably low. A brain MRI did not reveal any abnormalities. The patient's serum and CSF was negative for IgLON5-IgG using commercially available cell-based assay (Euroimmun, Germany). Standard CSF analysis results were within the normal range.

Diagnoses of NT1 with comorbid RBD and obstructive sleep apnea were set according to The International Classification of Sleep Disorders, Third Edition (ICSD-3, 2014) [1]. The first treatment was clomipramine because cataplexy was the patient's major problem. Cataplexy disappeared for a few months when taking $25 \mathrm{mg}$ but reoccurred occasionally afterwards. Based on the patient's complaints, we raised the dosage to $50 \mathrm{mg}$ of clomipramine and achieved a complete and permanent cataplexy resolution. Bilevel positive airway pressure in the automatic mode (expiratory pressure 4-16 mbar, pressure support 4-6 mbar) controlled obstructive sleep apnea (residual apnea-hypopnea index 1.6, T90 12\%) with mild improvement of EDS. To control RBD, the patient took $0.25 \mathrm{mg}$ of clonazepam before a night's sleep with a subjective improvement of RBD symptoms. After a year on this treatment, a polysomnography and Maintenance of Wakefulness Test (MWT) were performed because the patient asked for a renewal of his driving license. Second nocturnal polysomnography performed with bilevel positive airway pressure showed sleep of a very poor quality, SOREM, sleep fragmentation, and multiple RBD manifestations. Within the MWT, the subject fell asleep in all 4 tests with a mean sleep latency of $0.25 \mathrm{~min}$. However, sleepiness did not present a problem to the patient (other than the loss of his driving license). He refused taking any stimulants and he was satisfied with scheduled naps after meals. The last clinical control was done 2 years after the diagnosis and the treatment and clinical status of the patient were unchanged.

\section{Discussion}

Such a late manifestation of NT1 is unique. Considering the age, we suspected possible secondary causes. Attarian [6] summarizes case reports in which, most frequently, secondary narcolepsy presented with either abnormal MSLT or low CSF hypocretin level. Recently, an anti-IgLON5 disease has been described to be associated with narcolepsy [7]. However, based on clinical and physical findings as well as the negative cerebrospinal fluid, normal MRI findings, and stable clinical course, we consider possible secondary causes can be excluded.

Although MSLT and MWT confirmed severe EDS, the patient did not regard this as a problem. This is not very common in younger subjects, and we suppose that retirement might be the reason. As for other symptom characteristics, we could not distinguish any differences from NT1 with younger age at onset. Some clinical and polysomnographic findings indicate that young age at onset is associated with increased severity of the condition, with a higher frequency of cataplexy and decreased mean sleep latency on MSLT [8]. Other studies did not find any difference in symptom severity according to age of onset but suggested a decline of cataplexy frequency and a milder course in older age in general $[2,9]$. Our previous study looked into the health and quality of life in NT1 patients aged 60 years and older. These patients have been suffering from NT1 from a young age and have been treated for years. We did not find any major differences in social activities and quality of life in comparison to controls. However, NT1 subjects suffered from more frequent type 2 diabetes, arterial hypertension, and obesity and had lower physical fitness in old age [10].

In our patient, the diagnosis of NT1 was reached 5 months after the first symptoms. In the past, it was not rare that the diagnosis of narcolepsy was reached with a delay of 10 or more years [11]. The few previously reported cases of NC with an onset at an older age were initially 


\section{Case Reports in Neurology}

\begin{tabular}{l|l} 
Case Rep Neurol 2020;12:428-432 \\
\hline DOI: 10.1159/000510633 & $\begin{array}{l}\text { @) 2020 The Author(s). Published by S. Karger AG, Basel } \\
\text { www.karger.com/crn }\end{array}$ \\
\hline
\end{tabular}

Kovalská et al.: Rare Case of Late-Onset Narcolepsy Type 1

misdiagnosed and, thus, the diagnosis was delayed. In 1987, Kelly et al. [5] reported 2 cases: the first was a male with symptom onset at 72 years and the second a female at 84 years. In both cases, the diagnosis of $\mathrm{NC}$ was considerably delayed (15 years in the first case, misdiagnosed as secondary epilepsy). Later, other case reports of more or less typical NC with onset after 50 years were published. Quick et al. [4] reported a 74-year-at-onset male with unusual symptoms who did not fulfil the MSLT diagnostic criteria. Panda [12] reported a 57-year-atonset male and Chen et al. [13] a 60-year-at-onset woman, both initially misdiagnosed as psychomotor seizures. The only clinically clear case was reported by Krishnamurthy et al. [14] in a 59-year-at-onset male. The oldest patient (and the only one of those reported) with low hypocretin-1 in CSF was Chen et al.'s [13] patient.

\section{Conclusion}

Our patient shows that NT1 can manifest at a much older age than expected. Clinicians should be aware that narcolepsy symptoms might be covered by other health problems and lifestyle related to old age. Considering the potential for significant impairment of daily functioning and an increased risk of falls, early diagnosis, followed by efficient treatment, might greatly benefit the quality of life of elderly NT1 patients.

\section{Statement of Ethics}

The published research does comply with the guidelines for human studies and was conducted ethically in accordance with the World Medical Association Declaration of Helsinki. The subject has given their written informed consent to publish their case.

\section{Conflict of Interest Statement}

The authors have no conflicts of interest to declare.

\section{Funding Sources}

Supported by Ministry of Health of the Czech Republic, grant No. NU20-04-00088. All rights reserved.

\section{Author Contributions}

Petra Kovalská: summarizing data, patient examination, and writing the manuscript. Simona Dostálová: polysomnography and mean sleep latency test assessment. Hana Machová: first patient contact and patient examination. Petra Nytrová: laboratory data assessment. Eszter Maurovich Horvath: polysomnography and mean sleep latency test assessment. Karel Šonka: supervision, examination of the patient. 


\section{Case Reports in Neurology}

\section{References}

1 American Academy of Sleep Medicine. The International Classification of Sleep Disorders, Third Edition (ICSD-3). Darien, IL: American Academy of Sleep Medicine; 2014.

2 Dauvilliers Y, Montplaisir J, Molinari N, Carlander B, Ondze B, Besset A, et al. Age at onset of narcolepsy in two large populations of patients in France and Quebec. Neurology. 2001 Dec;57(11):2029-33.

3 Roth B. Narcolepsy and hypersomnia. Basel: Karger; 1980.

4 Quick AD, Black DN, Attarian HP. New-onset narcolepsy with cataplexy in a geriatric patient. Sleep Med. 2006 Sep;7(6):533.

5 Kelly JF, Lowe DC, Taggart HM. Narcolepsy in the elderly: a forgotten diagnosis. Age Ageing. 1987 Nov;16(6):405-8.

6 Attarian H. Narcolepsy in the older adult. In: Goswami M, Pandi-Perumal SR, Thorpy MJ, editors. Narcolepsy: A Clinical Guide. New York: Springer; 2010. p. 69-76. Available from: https://doi.org/10.1007/978-1-44190854-4_6

7 Gaig C, Iranzo A, Santamaria J, Graus F. The Sleep Disorder in Anti-lgLON5 Disease. Curr Neurol Neurosci Rep. 2018 May;18(7):41.

8 Dauvilliers Y, Gosselin A, Paquet J, Touchon J, Billiard M, Montplaisir J. Effect of age on MSLT results in patients with narcolepsy-cataplexy. Neurology. 2004 Jan;62(1):46-50.

9 Nevsimalova S, Buskova J, Kemlink D, Sonka K, Skibova J. Does age at the onset of narcolepsy influence the course and severity of the disease? Sleep Med. 2009 Oct;10(9):967-72.

10 Kovalská P, Kemlink D, Nevšímalová S, Maurovich Horvat E, Jarolímová E, Topinková E, et al. Narcolepsy with cataplexy in patients aged over 60 years: a case-control study. Sleep Med. 2016 Oct;26:79-84.

11 Morrish E, King MA, Smith IE, Shneerson JM. Factors associated with a delay in the diagnosis of narcolepsy. Sleep Med. 2004 Jan;5(1):37-41.

12 Panda S. Status cataplecticus as initial presentation of late onset narcolepsy. J Clin Sleep Med. 2014 Feb;10(2):207-9.

13 Chen W, Black J, Call P, Mignot E. Late-onset narcolepsy presenting as rapidly progressing muscle weakness: response to plasmapheresis. Ann Neurol. 2005 Sep;58(3):489-90.

14 Krishnamurthy VB, Nallamothu V, Singareddy R. An interesting case of late age at onset of narcolepsy with cataplexy. J Clin Sleep Med. 2014 Feb;10(2):203-5. 